\title{
Evaluation of abnormal uterine bleeding by transvaginal sonography, sonohysterography and correlation with endometrial histopathology
}

\author{
Parul Sinha*, Uma Gupta, Basma Waris, Aditi Dubey
}

Department of Obstetrics \& Gynaecology, Era’s Lucknow Medical College, Lucknow, India

Received: 20 July 2015

Accepted: 14 August 2015

\author{
*Correspondence: \\ Dr. Parul Sinha, \\ E-mail: drparulanand@gmail.com
}

Copyright: () the author(s), publisher and licensee Medip Academy. This is an open-access article distributed under the terms of the Creative Commons Attribution Non-Commercial License, which permits unrestricted non-commercial use, distribution, and reproduction in any medium, provided the original work is properly cited.

\begin{abstract}
Background: Abnormal uterine bleeding (AUB) in reproductive-age women is common, leading to one-third of outpatient visits by this population and this proportion crosses the two-third threshold in peri or post-menopausal group. Annually 5-10\% of women of reproductive age seek medical care for AUB, which negatively impacts quality of life. The aim of the present study was to study the role of transvaginal sonography (TVS) and sonohysterography (SHG) in abnormal uterine bleeding.

Methods: The present study was carried out at Department of Obstetrics and Gynaecology, Era's Lucknow Medical College, Lucknow in collaboration with Department of Radiology and Pathology, Era's Lucknow Medical College, Lucknow. It was a prospective study carried out over a period of 1 year. Detailed history regarding their present complaints, menstrual history along with thorough examination was noted on the proforma designed for the study. Those with active and heavy bleeding underwent TVS and D\&C for diagnostic and therapeutic purposes in the same sitting. However others without active bleeding underwent TVS, SIS in mid cycle and D\&C in premenstrual period.

Results: The present study was carried out at Department of Obstetrics and Gynaecology, Era's Lucknow Medical College, Lucknow in collaboration with Department of Radiology and Pathology, Era's Lucknow Medical College, Lucknow. It was a prospective study carried out over a period of 1 year. Detailed history regarding their present complaints, menstrual history along with thorough examination was noted on the proforma designed for the study. Those with active and heavy bleeding underwent TVS and D\&C for diagnostic and therapeutic purposes in the same sitting. However others without active bleeding underwent TVS, SIS in mid cycle and D\&C in premenstrual period. Conclusions: The findings in present study show a relative supremacy of SIS over TVS in diagnosis of uterine abnormalities in cases of abnormal uterine bleeding.
\end{abstract}

Keywords: Abnormal uterine bleeding, Endometrial histopathology, Sonohysterography, Transvaginal sonography

\section{INTRODUCTION}

Abnormal uterine bleeding (AUB) in reproductive-age women is common, leading to one-third of outpatient visits by this population and this proportion crosses the two-third threshold in peri or post-menopausal group. ${ }^{1,2}$ The most frequent culprits in this age group include anovulation, polycystic ovary syndrome, structural abnormalities (polyps, fibroids), endometrial hyperplasia, cancer, foreign bodies, pregnancy related complications, disorders of haemostasis, trauma and infection. ${ }^{3}$ Annually $5-10 \%$ of women of reproductive age seek medical care for AUB, which negatively impacts quality of life. ${ }^{4}$ Most women with AUB report that their leisure activities are at least moderately impacted by their bleeding and compared to women without AUB, women with AUB work almost 4 weeks less per year in the United States. 5,6 Approximately 6,00,000 hysterectomies are performed 
annually in the United States with $11 \%$ of these for AUB and $33 \%$ for leiomyoma. ${ }^{7}$ Goals of clinical management are primarily dependent upon attaining a correct etiological diagnosis. The history, physical and pelvic examination attempt to determine the site of bleeding and its source, Information gathered from this suggests what direction the investigation would take. Traditionally, dilatation and curettage (D\&C) is one of the commonest investigations employed in the evaluation of the causes of abnormal uterine bleeding. $\mathrm{D} \& \mathrm{C}$ is a blind procedure and the endometrium has to be sent to the pathologist to study histological patterns. The cooperation of the pathologist is important. However, the discomfort caused to the patient and the numerous costs involved place a burden on its use a screening tool. In the recent years, transvaginal sonography (TVS) has emerged as an important modality in investigating AUB. Transvaginal probe provides high resolution image of pelvic organs providing reliable information. Ultrasonography uses sound wave to create a view of the interior of the body so is free of any known adverse effect and thus can be repeated as often as required. It provides rapid assessment of uterine and adnexal pathology. The texture of endometrium can be evaluated for homogenecity or heterogenecity. Measurement of endometrium in AUB is helpful in determining the necessity for D\&C or further imaging study. Sonohysterography (SHG) also called as saline infusion sonography (SIS) is a simple technique that can be used to outline the contour of uterine cavity under real time ultrasound guidance. SHG is used to predict either the presence or absence of intramural lesion in uterine cavity and in distinguishing these lesion from subendometrial or myometrial lesion. Being simple, less invasive and less expensive, it can be used as an office procedure. The technique has shown promising results and it has been shown that SHG with endometrial biopsy had high sensitivity and high negative predictive value 8 . Keeping in view these finding, the present study was designed to correlate TVS and SHG with endometrial histopathology in patient with AUB.

The aim of the present study was to study the role of Transvaginal Sonography (TVS) and Sonohysterography (SHG) in abnormal uterine bleeding. The aim was fulfilled with the help of following objectives.

1. To evaluate the predictive values of non-invasive transvaginal sonography and sonohysetrography in abnormal uterine bleeding.

2. To correlate the results of transvaginal sonography and sonohysetrography with biopsy findings

3. To compare the diagnostic efficacy of non-invasive transvaginal sonography and sonohysetrography.

\section{METHODS}

The present study was carried out at Department of Obstetrics and Gynaecology, Era's Lucknow Medical College, Lucknow in collaboration with Department of Radiology and Pathology, Era's Lucknow Medical
College, Lucknow. It was a prospective study carried out over a period of 1 year.

\section{Inclusion criteria}

All women having AUB (a change in previously established menstrual pattern which adversely affects lifestyle) with age >18years were included in the study.

\section{Exclusion criteria}

Pregnant women and up to 6 weeks post-partum mothers, those having any pelvic inflammatory disease, severe cervical stenosis, thyroid disorder, coagulation disorder or any other medical illness and patients with IUCD in situ or those on hormonal contraceptives were excluded.

Detailed history regarding their present complaints, menstrual history along with thorough examination was noted on the proforma designed for the study. Those with active and heavy bleeding underwent TVS and D\&C for diagnostic and therapeutic purposes in the same sitting. However others without active bleeding underwent TVS, SIS in midcycle and D\&C in premenstrual period.

\section{Equipment}

All TVS examination was performed on an ultrasound imager [Logiq GE 5 PRO (2 dimensional) transvaginal probe $(6.5 \mathrm{MHz})]$.

\section{Transvaginal sonography}

The transducer was introduced into posterior fornix and uterus was scanned in longitudinal and coronal view with special emphasis on endometrium. Basic movements which were performed to visualize the pelvis using the transvaginal probe were:

1. Pushing pulling the entire probe

2. Rotating the probe $360^{\circ}$ allows scanning of the entire pelvis in all longitudinal planes

3. Tilting or angling the shaft

\section{Sonohysterography}

A 5-7 French Foley's catheter was introduced into the uterine cavity and fixed by inflating the balloon. The transvaginal probe was introduced into vagina and 10-15 $\mathrm{ml}$ of normal saline was injected to distend the endometrial cavity. Any intramural lesion like polyp, submucous fibroid, irregular endometrial thickening was looked for. Ultrasonographic evaluation was followed by dilatation and curettage. Endometrial tissue was preserved in $10 \%$ formalin and sent for histopathological examination. 


\section{Statistical analysis}

The statistical analysis was done using SPSS (Statistical Package for Social Sciences) Version 15.0 statistical Analysis Software. The values were represented in Number $(\%)$ and mean \pm SD.

\section{RESULTS}

The age of patients ranged from 22 to 55 years. Majority of the subjects $(n=34 ; 94.4 \%)$ were housewives. Majority of the subjects $(52.8 \%)$ had a history of complaints for $<6$ months followed by those having these complaints for 6 12 months $(25 \%)$. The incidence of AUB seemed to be increasing with increasing parity. There were only 2 $(5.6 \%)$ patients each in nulliparous and primiparous group. Clinically, $21(58.3 \%)$ patients gave the impression of normal uterus. A total of $7(19.4 \%)$ subjects had a bulky uterus. There were $8(22.2 \%)$ subject with 10-14 weeks uterus.

Table 1: Diagnosis based on transvaginal ultrasonographic findings $(n=36)$.

\begin{tabular}{|llll|}
\hline S.No. & Diagnosis & $\begin{array}{l}\text { No. of } \\
\text { cases }\end{array}$ & Percentage \\
\hline 1. & Normal & 17 & 47.2 \\
\hline 2. & Adenomyosis & 5 & 13.9 \\
\hline 3. & $\begin{array}{l}\text { Atrophic } \\
\text { endometrium }\end{array}$ & 1 & 2.8 \\
\hline 4. & Bulky uterus & 2 & 5.6 \\
\hline $\mathbf{5 .}$ & Hyperplasia & 5 & 13.9 \\
\hline 6. & Fibroid uterus & 4 & 11.1 \\
\hline 7. & Endometrial polyps & 2 & 5.6 \\
\hline
\end{tabular}

TVS revealed normal diagnosis in almost half, endometrial hyperplasia (13.9\%) and adenomyosis (13.9\%) were the most frequent findings detected. Saline infusion sonography revealed the majority of findings to be normal $(60 \%)$. A total of $12(40 \%)$ cases were observed to be abnormal.

Table 2: Distribution of subjects according to saline infusion sonography diagnosis $(n=60)$.

\begin{tabular}{|llll|}
\hline S.No & Diagnosis & $\begin{array}{l}\text { No. of } \\
\text { patients }\end{array}$ & Percentage \\
\hline 1. & $\begin{array}{l}\text { Endometrial } \\
\text { hyperplasia }\end{array}$ & 6 & 20.0 \\
\hline 2. & $\begin{array}{l}\text { Endometrial polyp } \\
\text { 3. }\end{array}$ & $\begin{array}{l}\text { Endometrial polyp } \\
\text { + hyperplasia }\end{array}$ & 6.7 \\
\hline 4. & $\begin{array}{l}\text { Small mucosal } \\
\text { fibroid }\end{array}$ & 3.3 \\
\hline 5. & Normal & 18 & 10.0 \\
\hline
\end{tabular}

Table 2 shows the saline infusion sonography in which endometrial hyperplasia $(20 \%)$ was the most common diagnosis followed by small submucosal fibroid (10\%).
Endometrial polyp was diagnosed in $2(6.7 \%)$ and in 1 $(3.3 \%)$ case, the diagnosis was endometrial polyp with hyperplasia.

\section{Finding on histopathology}

In $20(55.6 \%)$ cases the histopathological diagnosis was proliferative. Hyperplasia (25\%) was the next common finding. The correlations of histopathologic diagnoses were done with TVS and SIS for individual diagnosis. TVS diagnosis for histopathological proliferative case was observed to be normal in majority $(n=11 ; 55 \%)$. SIS was found to be normal in $12(70.6 \%)$ cases.

Table 3: Diagnostic efficacy of TVS against HPE $(\mathbf{n}=36)$.

\begin{tabular}{|c|c|c|c|}
\hline TVS Findings & \multicolumn{2}{|c|}{ HPE Findings } & Total \\
\hline & Abnormal & Normal & \\
\hline Abnormal & 8 & 11 & 19 \\
\hline Normal & 3 & 14 & 17 \\
\hline Total & 11 & 25 & 36 \\
\hline
\end{tabular}

$\mathrm{x}^{2}=2.592(\mathrm{df}=1) ; \mathrm{p}=0.112$

\begin{tabular}{|l|l|l|l|l|} 
Sensitivity & Specificity & PPV & NPV & DA \\
\hline $\mathbf{7 7 . 7}$ & 56.0 & 42.1 & 82.4 & 61.1 \\
\hline
\end{tabular}

On comparing the diagnostic efficacy of TVS against histopathology, its sensitivity, specificity, PPV, NPV and diagnostic accuracy was observed to be $72.7 \%, 56.0 \%$, $42.1 \%, 82.4 \%$ and $61.1 \%$ respectively. On comparing the data statistically, this association was not significant statistically.

Table 4: Diagnostic efficacy of SIS against HPE $(n=36)$.

\begin{tabular}{llll|} 
& SIS Findings & \multicolumn{1}{c}{ HIPE Findings } & Total \\
& Abnormal & Normal & \\
\hline Abnormal & 7 & 5 & 12 \\
\hline Normal & 2 & 16 & 18 \\
\hline Total & 9 & 21 & 30 \\
\hline
\end{tabular}

$\mathrm{x}^{2}=7.646(\mathrm{df}=1) ; \mathrm{p}=0.006$

\begin{tabular}{|l|l|l|l|l}
\hline Sensitivity & Specificity & PPV & NPV & DA \\
\hline 77.8 & 76.2 & 58.3 & 88.9 & 76.7
\end{tabular}

On comparing the diagnostic efficacy of SIS against histopathology, its sensitivity, specificity, PPV, NPV and diagnostic accuracy was observed to be $77.8 \%, 76.2 \%$, $58.3 \%, 88.9 \%$ and $76.7 \%$ respectively.

\section{Additional information provided by TVS and SIS}

Although HPE was taken as the gold standard, yet information provided by TVS and SIS was useful in 
making final diagnosis, especially in cases of adenomyosis and fibroid uterus which remained undiagnosed on HPE.

Final diagnosis revealed maximum cases to be anovulatory dysfunctional uterine bleeding $(n=14$ : $38.9 \%)$. Another $3(8.3 \%)$ Ovulatory dysfunctional uterine bleeding $(n=3: 8.3 \%)$.Among different abnormalities, fibroid uterus and endometrial hyperplasia $(\mathrm{n}=5: 13.9 \%)$ were most common. There were 2 cases of adenomyosis (5.6\%). Adenomyosis with endometrial hyperplasia, adenomyosis with endometrial polyp, atrophic hyperplasia, atrophic endometrium, endometrial polyp, endometrial polyp with endometrial hyperplasia, fibroid uterus with adenomyosis and tubercular adenometritis were reported in $1(2.8 \%)$ case each.

Table 5: Final diagnosis (on the basis HPE+TVS+SIS Findings) $(\mathbf{n}=36)$.

\begin{tabular}{|llll|}
\hline $\begin{array}{l}\text { Final } \\
\text { Diagnosis }\end{array}$ & $\begin{array}{l}\text { No. of } \\
\text { patients }\end{array}$ & $\%$ & Basis of diagnosis \\
\hline Adenomyosis & 2 & 5.6 & TVS \\
\hline $\begin{array}{l}\text { Atrophic } \\
\text { endometrium }\end{array}$ & 1 & 2.8 & TVS and HPE \\
\hline $\begin{array}{l}\text { Endometrial } \\
\text { hyperplasia }\end{array}$ & 5 & 13.9 & TVS/SIS/HPE \\
\hline $\begin{array}{l}\text { Endometrial } \\
\text { polyp }\end{array}$ & 1 & 2.8 & TVS/SIS \\
\hline $\begin{array}{l}\text { Fibroid } \\
\text { uterus }\end{array}$ & 5 & 13.9 & SIS/TVS \\
\hline $\begin{array}{l}\text { Tubercular } \\
\text { endometritis }\end{array}$ & 1 & 2.8 & HPE \\
\hline $\begin{array}{l}\text { DUB } \\
\text { anovulatory }\end{array}$ & 14 & 38.9 & $\begin{array}{l}\text { HPE (other } \\
\text { pathologies ruled out } \\
\text { by } \text { diagnosis confirmed } \\
\text { by HPE) }\end{array}$ \\
\hline $\begin{array}{l}\text { DUB } \\
\text { ovulatory }\end{array}$ & 3 & 8.3 & $\begin{array}{l}\text { HPE (other } \\
\text { pathologies ruled out } \\
\text { by TVS and SIS } \\
\text { diagnosis confirmed } \\
\text { by HPE) }\end{array}$ \\
\hline
\end{tabular}

Table 6: Incremental Efficacy of Combined Diagnosis over HPE alone $(n=36)$.

\begin{tabular}{|c|c|c|c|c|}
\hline \multirow[t]{2}{*}{ HPE alone } & \multicolumn{3}{|c|}{$\begin{array}{l}\text { Combined Diagnostic } \\
\text { Findings }\end{array}$} & \multirow[t]{2}{*}{ Tota } \\
\hline & Abnormal & \multicolumn{2}{|c|}{ Normal } & \\
\hline Abnormal & 9 & \multicolumn{2}{|c|}{2} & 11 \\
\hline Normal & 10 & \multicolumn{2}{|c|}{15} & 25 \\
\hline Total & 19 & \multicolumn{2}{|c|}{17} & 36 \\
\hline \multicolumn{5}{|c|}{$\mathrm{x}^{2}=5.361(\mathrm{df}=1): \mathrm{p}=0.021$} \\
\hline Sensitivity & Specificity & PPV & NPV & DA \\
\hline 47.4 & 88.2 & 81.8 & 60.0 & 66.7 \\
\hline
\end{tabular}

As compared to combined efficacy, HPE alone had a diagnostic accuracy of $66.7 \%$ alone. Thus combined diagnosis was useful in enhancing the HPE accuracy by $50 \%$.

\section{DISCUSSION}

The aim of the present study was to observe the role of TVS and SIS in AUB. For this purpose a total of 36 women with complaints of abnormal uterine bleeding were enrolled. Pregnant women and up to 6 weeks postpartum women mother were excluded as they might be having bleeding owing to some antenatal or postpartum disorders and those suffering from any pelvic inflammatory disease, severe cervical stenosis, thyroid disorder, coagulation disorder or any other chronic illness were also excluded as they all might be having the disease owing to some physiological reasons. For the similar reason those having IUCD in situ or those on hormonal contraceptives were excluded from the study.

On the basis of TVS ultra-sonographic findings a total of 17 cases were diagnosed as normal (table 1). Among different abnormalities reported on USG adenomyosis and hyperplasia and were most common $(n=5,13.9 \%$ each); fibroid uterus $(n=4 ; 11.1 \%)$ was the next most common finding followed by 2 cases $(5.6 \%)$ each of bulky uterus and endometrial polyps. There was $1(2.8 \%)$ case which was diagnosed to be having atrophic endometrium.

On SHG too, majority ( $\mathrm{n}=18 ; 60 \%$ ) (Table 2) subjects were diagnosed as normal. Among different abnormalities-endometrial hyperplasia was most common diagnosis $(n=6 ; 20 \%)$, small sub mucosal fibroid $(n=3$; $10 \%$ ) was the next most common finding while endometrial polyp $(\mathrm{n}=2 ; 6.7 \%)$ and endometrial polyp with hyperplasia $(n=1 ; 3.3 \%)$ were the least common finding. A total of 6 cases did not undergo SHG owing to cervical stenosis or distension problems.

Out of a total of 11 cases detected to be having abnormalities on HPE, TVS could diagnose 8 cases truly. However the false positivity rate of TVS as observed in present study was quite high, there were 11 false positive cases in whom abnormalities have been diagnosed on TVS, but HPE confirmed them to be normal. This contributed to lowering of the positive predictive value of the test significantly $(\mathrm{PPV}=42.1 \%)$ (Table 3$)$. As regards the normal findings, out of 25 cases diagnosed to be normal on histopathology, the TVS diagnosis could match in only 14 , thus making it to be $56 \%$ specific. Only $3 \%$ cases which were positive on HPE did not correlate in TVS findings. This negative predictive value was observed to be $82.4 \%$. The diagnostic accuracy of the test was $61.1 \%$. In the study of Islam et al., it was observed that TVS had a very good diagnostic value in finding normal endometrium i.e. proliferative and secretory phase. ${ }^{9}$ In their study, TVS picked up $10(5 \%)$ false positive cases and no false negative case was detected. 
However, in present study, TVS was shown to be performing poorly. In present study, as many as a total of $11(30.6 \%)$ case were diagnosed to be false positive on TVS while a total of $3(8.3 \%)$ cases were diagnosed false negatively. In present study, TVS was found to be more sensitive the specific. These findings correlate with the findings of Islam et al., who also observed that TVS was more sensitive that specific. ${ }^{9}$ However, the false positivity of the test was quite high; this was because in present study the incidence of histopathologic abnormalities was less than one-third. In the study of Dasgupta et al., the TVS findings suggestive of hyperplasia were quite common on USG. ${ }^{10}$

As regards SIS, a total of 6 patients did not undergo the procedure. The findings in present study are in consonance with the findings of Aslam et al., who too observed majority of their patients with abnormal uterine bleeding to be having normal uterus and encountered malignancy in only 1 case. $^{11}$ In terms of uterine abnormalities, they had observed the diagnostic efficacy of TVS in terms of sensitivity, specificity, PPV, NPV and diagnostic accuracy to be $71.43 \& 67.7 \%, 54.35 \&$ $81 / 48 \%$ and 695 respectively (Table 4). In present study, on the same parameters, we find the diagnostic efficacy of TVS to be $72.7 \%, 56 \%, 42.1 \%, 82.4 \%$ and $61.1 \%$ (Table 3) respectively. In both the studies, the sensitivity of TVS was observed to be higher as compared to specificity while owing to low prevalence; the positive predictive value is poor in both the studies. In the study of Aslam et al., the diagnostic performance of SIS was observed to be $92.86 \%$ sensitive, $89.65 \%$ specific, with positive predictive value of $86.67 \%$ and negative predictive value of $94.54 \% .{ }^{11}$ The diagnostic accuracy observed by them was a high $91 \%$. However; in present study we could not achieve the similar level of performance by SIS. In present study it was $77.8 \%$ sensitive, $76.2 \%$ specific, with a PPV of $58.3 \%$ and a NPV pf $88.9 \%$ while the diagnostic accuracy was $76.7 \%$ (Table 4). In present study apart from positive predictive value, for all the parameters the efficacy of SIS was over $75 \%$. Despite this difference between two studies, in both the studies SIS was found to be more efficient in detection of uterine abnormalities in cases of abnormal uterine bleeding as compared to TVS. Although the findings, obtained by Mathew et al., provide a better efficacy of SIS as compared to the findings in present study. ${ }^{12}$ They have reported the sensitivity, specificity, positive and negative predictive values for TVS to be $72.44 \%, 100 \%, 100 \%$ and $74 \%$ respectively, while for SIS the corresponding figures were $91.4 \%, 92.6 \%, 89.3 \%$ and $94.1 \%$. In present study, no such distinguishing difference was observed which might be attributed to smaller size of study sample. Yildizhan et al too observed a better efficacy of SIS over TVS in detection of both uterine polyps and fibroids. ${ }^{13}$ No doubt, SIS was a superior technique as compared to TVS but at the same time, its inability to be carried out in all cases is one of the restrictions for its use in all the patients. Epstein et al have also expressed similar reservations on SIS use when they found that SIS failed in approximately $20 \%$ of their cases owing to similar reasons as encountered in present study. ${ }^{14}$ This is one big limitation in the use of SIS as a routine and preliminary tool for diagnosis. One of the limitations of the present study was its small sample size. With this limited same size we could not get a true representation of the incidence of various uterine abnormalities and hence the results have a limited application. Despite this limited application, the trends obtained by us in general indicate that SIS is a better diagnostic tool as compared to TVS. However, in preparation of final diagnosis we found that the combined role of all the three techniques is quite useful. The findings in present study, are indicators for a larger study to be carried out at our centre so as to substantiate the results and with the cumulative evidence provide a much better opportunity to correlate and compare the two techniques.

\section{CONCLUSIONS}

The findings in present study, show a relative supremacy of SIS over TVS in diagnosis of uterine abnormalities in cases of abnormal uterine bleeding. However, owing to limitations of sample size and time the relationship needs further exploration with larger spectrum of diagnoses.

Funding: No funding sources Conflict of interest: None declared Ethical approval: Not required

\section{REFERENCES}

1. Cannon MJ. Endometrial resection for treatment of abnormal uterine bleeding. Obstet Gynecol. 2000;102:453-62.

2. Webster SD, Canon Z. Cytohistological correlation in patients with dysfunctional uterine bleeding. Biomed Sci Intrum. 2000;36:367-72.

3. Bradley LD, Skaznik-Wikiel ME. Investigation of Abnormal Uterine Bleeding in Peri- and Postmenopausal Women. Menopause Management. 2008;6:13-22.

4. Kjerulff KH, Erickson BA, Langenberg PW. Chronic gynecological conditions reported by US women: findings from the National Health Interview Survey, 1984 to 1992. Am J Public Health. 1996;86:195-9.

5. Frick KD, Clark Ma, Steinwachs DM, Langenberg P, Stovall D, Munro MG, Dickersin K; STOP-DUB Research Group. Financial and quality-of-life burden of dysfunctional uterine bleeding among women agreeing to obtain surgical treatment. Women's Health Issues. 2009;19(1):70-8.

6. Cote I, Jacobs P, Cumming D. Work loss associated with increased menstrual loss in the United States. Obstetrics \& Gynecology. 2002;100:683-7

7. Farquhar CM, Steiner CA. Hysterectomy rates in the United States 1990-1997. Obstet Gynecol. 2002;99:229-34. 
8. Mihm LM, Quick VA, Jonathan RN, Cohnors AF, Connors AF, Finnerty JJ. The accuracy of endometrial biopsy and saline sonohysterography in the determination of the cause of abnormal uterine bleeding. Am J Obstet Gynaecol. 2002;186:858-66.

9. Islam A, Ghazala. Trnasvaginal sonography; Its specificity and sensitivity in abnormal uterine bleeding. Prof. Med. J. 2009;16(1):127-34.

10. Dasgupta Subhankar, Chakraborty Barunoday, Karim Rejaul, Aich Ranen Kanti, Mitra Pradip Kumar, Ghosh Tarun Kumar. Abnormal Uterine Bleeding in Peri-Menopausal Age: Diagnostic Options and Accuracy. J. Obs. Gyn. 2011:184-94.

11. Aslam M, Ijaz L, Tariq S, Shafqat K, Meher-unNisa, Ashraf R, Kazmi T. Comparison of Transvaginal Sonography and Saline Contrast Sonohysterography in Women with Abnormal Uterine Bleeding: Correlating with Hysteroscopy and Histopathology. International Journal of Health Sciences, Qassim University. 2007;1(1):17-24.

12. Mathew M, Gowri V, Rizvi SG. Saline infusion sonohysterography - an effective tool for evaluation of the endometrial cavity in women with abnormal uterine bleeding. Acta Obstet Gynecol Scand. 2010;89(1):140-2.

13. Yildizhan B, Yildizhan R, Ozkesici B, Suer N. Transvaginal ultrasonography and saline infusion sonohysterography for the detection of intra-uterine lesions in pre- and post-menopausal women with abnormal uterine bleeding. J Int Med Res. 2008;36(6):1205-13.

14. Epstein, E., Ramirez, A., Skoog, L. and Valentin, L. Transvaginal sonography, saline contrast sonohysterography and hysteroscopy for the investigation of women with postmenopausal bleeding and endometrium > $5 \mathrm{~mm}$. Ultrasound Obstet Gynecol. 2001;18:157-62.

Cite this article as: Sinha $\mathrm{P}$, Gupta U, Waris B, Dubey A. Evaluation of abnormal uterine bleeding by transvaginal sonography, sonohysterography and correlation with endometrial histopathology. Int J Reprod Contracept Obstet Gynecol 2015;4:1374-9. 